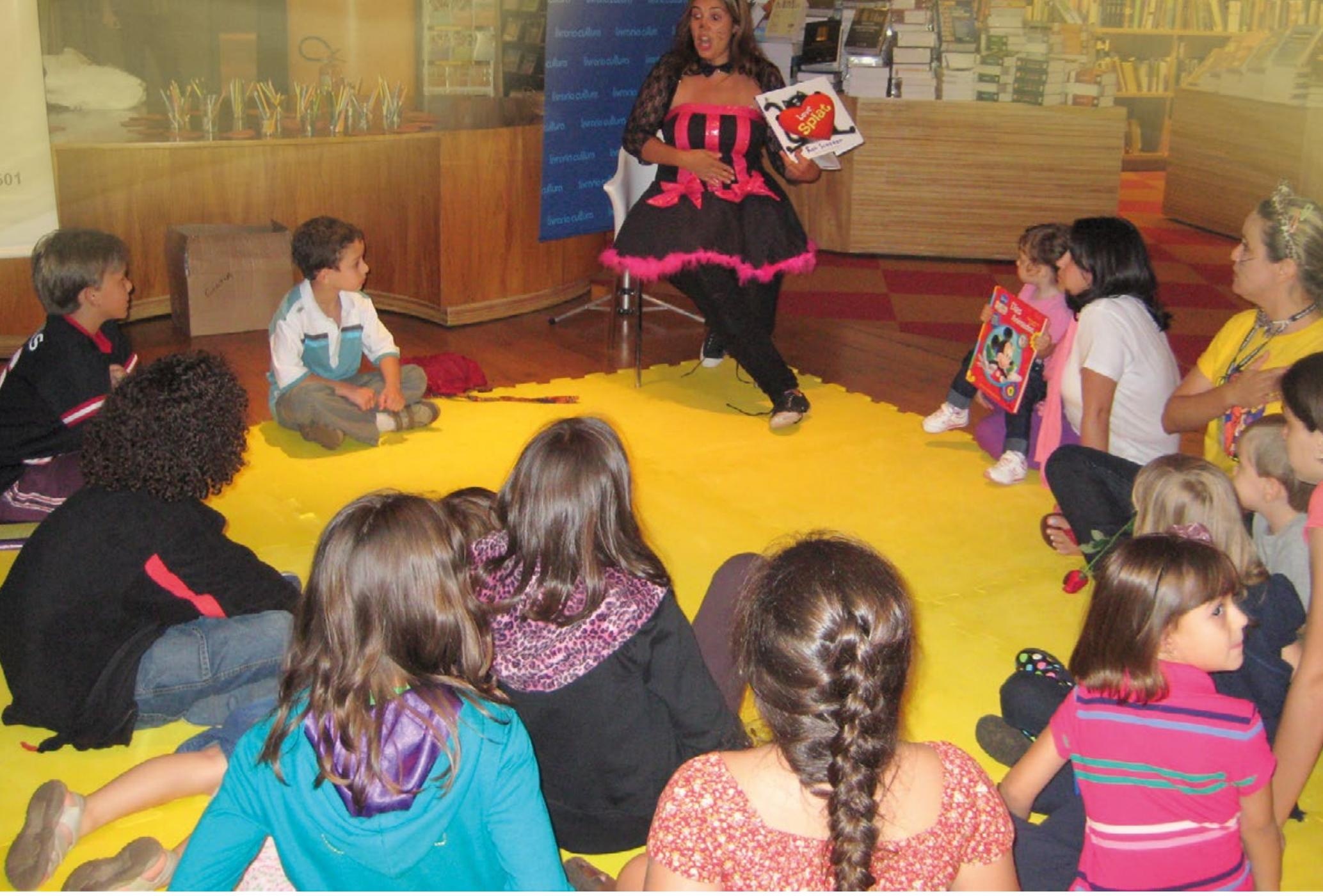

\title{
SEQUÊNCIA DIDÁTICA DO GÊNERO DISCURSIVO CONTO NO ENSINO FUNDAMENTAL: RELATO DE EXPERIENNCIA
}

\section{RESUMO}

Este artigo tem o objetivo de apresentar uma sequência didática do gênero discursivo conto que foi aplicada em uma turma do $7^{\circ}$ Ano do Ensino Fundamental em uma escola estadual no município de Natal/RN. A sequência didática durou doze aulas de 50 minutos e foi desenvolvida em seis etapas. Uma primeira abordagem ao gênero foi feita através da leitura. A sequência didática foi concluída com a produção escrita de um conto e uma autoavaliação. Ela também incluiu o estudo da biografia do autor e uma abordagem das principais características do gênero, tais como a análise de operadores de coesão temporal que contribuem para a tessitura do texto narrativo. Os resultados indicaram que a sequência foi bem sucedida, pois auxiliou os estudantes a compreenderem melhor as características do gênero discursivo conto.

Palavras-chave: Gênero discursivo conto. Sequência didática. Leitura. Escrita. 


\section{INTRODUÇÃOO}

Leitura e escrita são competências e habilidades que podem ser desenvolvidas e aprimoradas na escola. De modo geral, ao iniciar os estudos formais, os jovens podem ter contato com a leitura e escrita de contos, que são "[...] uma das formas mais universais de transmissão cultural, registrando, entre outras coisas, [...] valores, costumes [...]" (D'ONOFRIO, 2007, p. 92), e esse fato pode justificar nossa pesquisa. Este trabalho visa apresentar e discutir uma seqüência didática do gênero discursivo conto que foi aplicada na turma do $7^{\circ}$ ano "B" - Matutino da Escola Estadual Professor José Fernandes Machado, no município de Natal/RN sob a supervisão da professora Leidivânia Mendes Melchuna. A sequência didática proposta teve a duração de doze aulas de 50 minutos e foi desenvolvida em seis etapas. O referencial teórico que amparou nossa investigação foi Dolz, Noverraz e Schneuwly (2004) com o conceito de sequência didática.

\section{FUNDAMENTAÇÃO TEÓRICA}

Nossa fundamentação teórica envolve basicamente o conceito de sequência didática. Esse conceito teórico, usado para o ensino do gênero conto, encontra-se embasado na teoria de Dolz, Noverraz e Schneuwly (2004, p. 82). De acordo com esses autores, "uma sequência didática é um conjunto de atividades escolares organizadas de maneira sistemática em torno de um gênero textual oral ou escrito", e tem o objetivo de ajudar os alunos a dominarem textos orais e escritos, permitindo-lhes, assim, escrever ou falar de uma maneira mais adequada às situações comunicativas. Optamos por trabalhar com os alunos o Conto Literário.

\section{METODOLOGIA}

Aplicamos uma sequência didática composta de seis etapas. A primeira etapa viabilizou ao aluno um contato inicial com o gênero em questão através da leitura de um conto de José Saramago. Em seguida, foi apresentado um vídeo no qual o autor declamava o conto e foi solicitada uma produção textual referente ao gênero. Na segunda etapa, foi apresentada a biografia do autor e, na terceira etapa, a turma foi dividida em grupos de cinco estudantes para fazerem a leitura de um outro conto de autoria de Clarice Lispector. Na quarta etapa, foram abordadas as principais características do gênero. Na quinta etapa, apresentamos aos alunos os operadores de coesão temporal. $\mathrm{Na}$ sexta e última etapa, os alunos foram convidados a produzirem um conto e a realizarem uma autoavaliação a partir de uma tabela de correção elaborada pelo professor supervisor. Essa tabela foi composta de questões referentes à competências linguísticas, como: Ortografia, Acentuação gráfica, Concordância etc. As etapas serão detalhadas a seguir.

\section{A PRIMEIRA ETAPA: CONTATO INICIAL COM $O$ GÊNERO ATRAVÉS DA LEITURA}

A primeira etapa teve como objetivo viabilizar aos alunos um contato inicial com o gênero em questão. Essa fase teve a duração de duas aulas de 50 minutos. Foi feita a leitura do conto A maior flor do mundo, de autoria de José Saramago, e apresentamos um vídeo de curta duração baseado nesse conto. Em seguida, foram feitas algumas questões referentes à maneira como o texto era organizado, se as personagens dos contos eram reais ou fictícias, como era a linguagem usada, etc. Para concluir essa etapa, foi solicitado que os estudantes fizessem, em casa, a produção de um texto narrativo. 


\section{A SEGUNDA ETAPA: LEITURA DE BREVE BIOGRAFIA DO AUTOR DO CONTO (JOSÉ SARAMAGO)}

A segunda etapa constituiu-se de uma breve exposição sobre a vida e obra do escritor José Saramago. Perguntamos aos alunos se algum deles conheciam esse autor, já que ele é o único escritor lusófono vencedor do Prêmio Nobel de Literatura. Simultaneamente, foram realizadas perguntas como quem foi Saramago, onde ele nasceu, que tipo de literatura ele escreveu, etc.

\section{A TERCEIRA ETAPA: LEITURA DE OUTRO EXEMPLAR DO GÊNERO CONTO (CLARICE LISPECTOR)}

Fizemos a leitura do conto Felicidade Clandestina, da escritora Clarice Lispector. A sala foi dividida em grupos contistuídos por cinco alunos, nos quais cada um deveria, após a leitura, selecionar um representante para desenvolver uma breve explanação a respeito dos principais aspectos observados. Foram feitas perguntas referentes ao tempo e ao espaço da história, a quantidade de peronagens, características do narrador, etc. Ao final, as professoras apresentaram uma pequena biografia dessa escritora brasileira.

\section{A QUARTA ETAPA: CARACTERÍSTICAS ESTRUTURAIS DO GÊNERO CONTO}

A apresentação do gênero foi feita por meio de um slide em PowerPoint, no qual as principais características do gênero foram abordadas, lembrando aos alunos que tudo no conto é reduzido: espaço, tempo, personagens, etc. Dando sequência às atividades propostas, apresentamos o conto. Depois, foram discutidas algumas questões referentes à história a ser lida. Ao final, projetamos o vídeo baseado no conto A pequena vendedora de fósforos. Propusemos questões para discussão referentes ao título do conto, ao desfecho, etc.

\section{A QUINTA ETAPA: OPERADORES DE COESÃO TEMPORAL}

A quinta etapa visou levar aos alunos a compreensão e a importância a respeito dos operadores de coesão temporal para a tessitura do texto. Sendo assim, trabalhamos com os alunos os conectores coesivos, sendo solicitado a eles que, ao retomar a leitura do conto Felicidade Clandestina, identificassem esses conectores. Em seguida, discutimos a importância desses elementos linguísticos para a construção do sentido e enredo na narrativa.

\section{A SEXTA E ÚLTIMA ETAPA: PRODUÇÃO INDIVIDUAL DO GÊNERO CONTO E AUTOAVALIAÇÃO}

Esta etapa representa a culminância de todos os processos percorridos durante a sequência. Nela, os alunos devem produzir um conto individualmente e realizarem uma autoavaliação. Esse momento também é o ideal para que sejam trabalhadas questões referentes às competências linguísticas, como ortografia, acentuação gráfica, concordância, entre outros.

\section{RESULTADOS E DISCUSSÃO}

Podemos afirmar que os resultados da aplicação dessa sequência didática foram positivos, pois as atividades foram desenvolvidas em sua dimensão discursiva e em conjunto, de

organização e reorganização de sentidos, e isso fez com que a maioria dos alunos se sentissem realmente motivados a ler, participando das leituras coletivas e interagindo com as professoras. 


\section{CONSIDERAÇÕES FINAIS}

O nosso objetivo principal diante deste trabalho foi efetuar a exposição de uma sequência didática aplicada em uma turma do $7^{\circ}$ Ano do Ensino fundamental a partir do gênero conto. A sequência didática aqui abordada visou o contato e a compreensão do gênero textual conto mostrando suas características como: finalidade, suporte, interlocutores, estrutura, linguagem, de modo que esses elementos ajudassem o aluno tanto a conhecer quanto a reconhecer o gênero, compreendendo efetivamente sua forma e conteúdo. Por fim, não podemos deixar de mencionar que é fundamental valorizar essas experiências feitas em sala e que estão dando certo, para que, de alguma forma, elas possam servir de exemplo para outros profissionais da área. Portanto, não só estaremos unidos nessa caminhada como contribuindo para uma educação de qualidade e servindo de exemplo para muitos alunos que desejam seguir nesse ramo acadêmico.

\section{ABSTRACT}

This paper aims to present a didatic sequence of the discursive gender "tale" which was developed in a 7 th year grade of a state school in the city of Natal, RN, Brazil. The didactic sequence consisted of twelve 50 minutes classes and it was developed in six stages. A first approach to the gender tale involved reading one of them. The didactic sequence was concluded with students writing a tale and performing a self-evaluation. It also included the author's biography study and a approach of the main gender's characteristics, such as an analysis of timing cohesive elements, which contribute to the narrative sequence. Results indicate that the didactic sequence was well succeed since it helped students to understand better the characteristics of the discursive gender "tale".

Key words: Discursive gender tale. Didatic sequence. Reading. Writing. 


\section{REFERÊNCIAS}

ANDERSEN, Hans Christian. A pequena vendedora de fósforos. Rio de Janeiro: Zahar, 2013.

ARAÚJO, Maria José. Práticas literárias na escola a partir do gênero conto. Revista de divulgação científica em Língua Portuguesa, Linguística e Literatura, São Paulo, v. 11, n. 18, 2015. Disponível em: <http://www.letramagna.com/artigos_18/artigo6_18.pdf>. Acesso em: 5 out. 2017.

EDUCA REDE. Como trabalhar com contos. Disponível em: <http://www.rea.net.br/ educarede/2013/05/21/como-trabalhar-com-contos>. Acesso em: 5 out. 2017.

DOLZ, Joaquim; NOVERRAZ, Michele; SCHNEUWLY, Bernard. Seqüências didáticas para o oral e a escrita: apresentação de um procedimento. In: Gêneros orais e escritos na escola. Campinas, SP: Mercado de Letras, 2004.

D’ONOFRIO, Salvatore. Forma e sentido do texto literário. São Paulo: Ática, 2007.

LISPECTOR, Clarice. Felicidade clandestina. Rio de Janeiro: Rocco, 1998.

SARAMAGO, José. A maior flor do mundo. Ilustrações de João Caetano. São Paulo: Companhia das Letrinhas, 2001. 


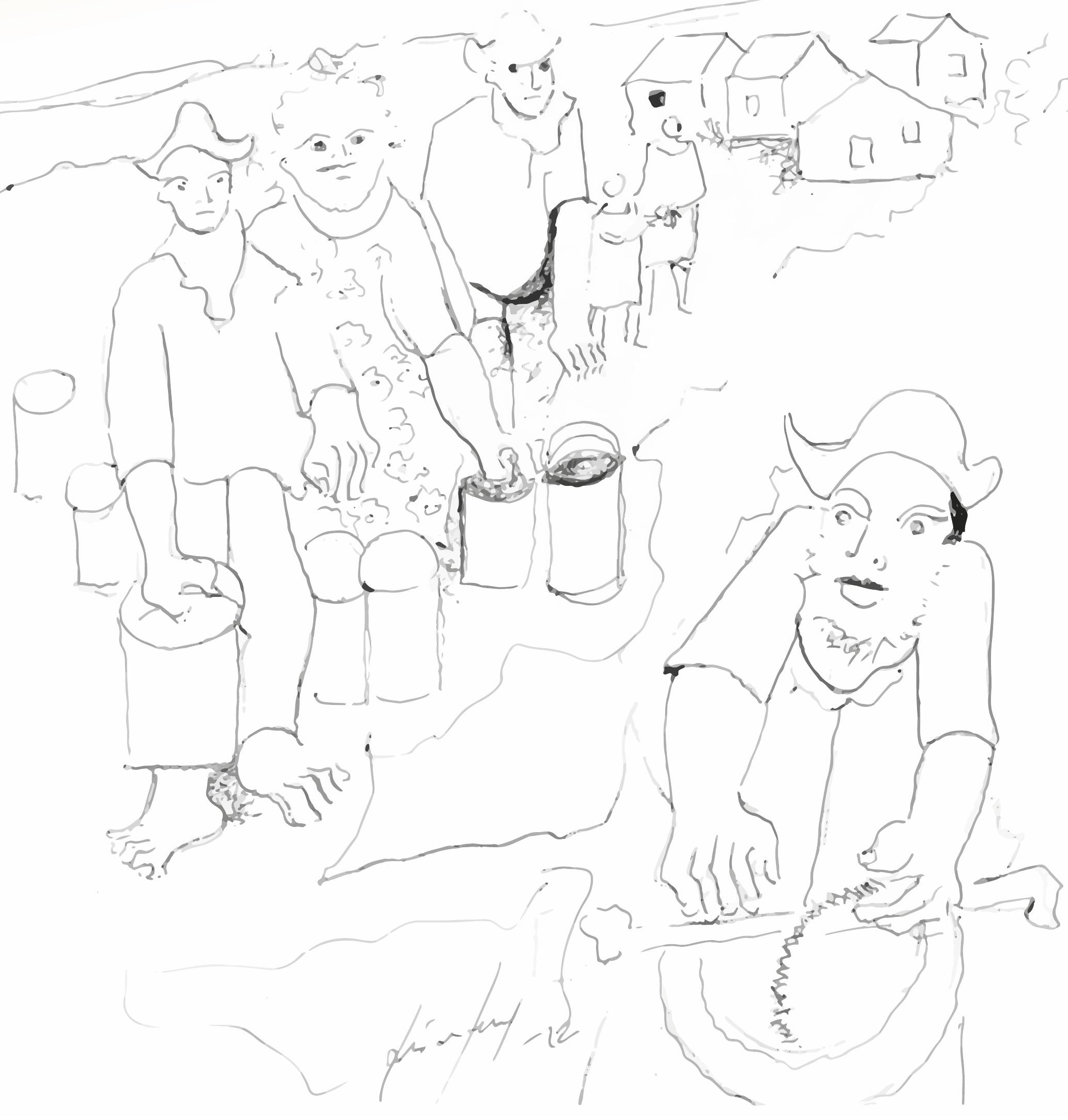

